\title{
OPEN Perioperative symptomatic venous thromboembolism after immediate chemoprophylaxis in patients with pelvic and lower-extremity fractures
}

\author{
Jin Kyu Lee ${ }^{1}$, Ja Wook Koo ${ }^{1}$, Soo-Young Jeong $\mathbb{1}^{1}$, Sihoon Choi ${ }^{1}{ }^{1}$, Ki-Chul Park ${ }^{2}$ \& \\ Kyu-Tae Hwang ${ }^{1 *}$
}

The purpose of this study was to investigate the incidence of symptomatic venous thromboembolism (VTE) after chemoprophylaxis in patients with pelvic and lower-extremity fractures, and to identify risk factors for VTEs in this subgroup of patients. To detect VTE, multi-detector computed tomography (CT) angiography was performed. Of 363 patients assessed, the incidence of symptomatic VTE was $12.4 \%$ ( 45 patients), and the incidence of symptomatic PE was $5.2 \%$ (19 patients). For the risk-factor analysis, a higher Charlson comorbidity index $(p=0.037)$, and a history of external fixator application $(p=0.007)$ were associated with increased VTE risk. Among patients who had VTE, male sex $(p=0.017)$, and above-the-knee fractures $(p=0.035)$ were associated with increased pulmonary embolism (PE) risk. In conclusions, the incidence of VTE in post-traumatic patients is not low after chemoprophylaxis. Risk factors for VTE and PE are different among patients with pelvic and lower-extremity fractures.

Deep vein thrombosis (DVT) and pulmonary embolism (PE), known as venous thromboembolism (VTE), occur every year in approximately 900,000 people in the United States, with a death toll of $300,000^{1}$. Patients with severe trauma are at risk of VTE, and in $25 \%$ of severely traumatised patients, coagulopathy occurs immediately after injury, resulting in a 5 -fold increase in mortality ${ }^{2-6}$. The reported incidence of post-traumatic VTE ranges between $2.6 \%$ and $63 \%$ depending on factors including patients' characteristics (e.g., injury severity and injury pattern), type of VTE prevention used, sensitivity of the screening test, and other factors ${ }^{7-10}$. Prophylaxis of VTE is based mainly on physical therapy and chemotherapy ${ }^{11-14}$, and chemotherapy is more efficacious than physical therapy in terms of lowering the incidence of $\mathrm{VTE}^{15}$. Most studies of the incidence of VTE in post-traumatic patients include various patterns and severity of trauma, and it is difficult to estimate the true incidence of VTE in specific types of fractures or provide an optimal guideline for prophylaxis of VTE in this subgroup of patients ${ }^{16-18}$. Furthermore, identification of risk factors has proven useful in defining high-risk patients and corresponding prophylaxis appears mandatory for all trauma patients.

The purpose of this study was to investigate the incidence of symptomatic VTE after chemoprophylaxis in patients with pelvic and lower-extremity fractures. Multivariate logistic regression was also performed to identify risk factors for VTEs in this subgroup of patients.

\section{Results}

Of 363 patients assessed, 212 were male and 151 were female, with an average age of 56 years (range, 21-73 years). Demographic and clinical data including patients' comorbidities and Charlson index values are presented in Table 1 . There were significantly higher proportion of patients with a history of peripheral vascular disease in patients who had VTE compared to patients without VTE $(31.1 \%$ vs $1.3 \%, p<0.001)$. There were 28 cases of acetabulum fracture, 17 cases of pelvic bone fracture, 174 cases of femur fracture, 137 cases of tibia fracture, and

\footnotetext{
${ }^{1}$ Department of Orthopedic Surgery, Hanyang University Hospital, Seongdong-gu, Seoul, Republic of Korea. ${ }^{2}$ Department of Orthopedic Surgery, Hanyang University Guri Hospital, Guri, Gyeonggi-do, Republic of Korea. *email: hwangkt@hanyang.ac.kr
} 


\begin{tabular}{|l|l|l|c|}
\hline Variables & VTE $(-)(\mathbf{N}=318)$ & VTE $(+)(\mathbf{N}=\mathbf{4 5})$ & $P$-value \\
\hline Age & $54(21-71)$ & $58(24-73)$ & 0.228 \\
\hline Body mass index & $23.53(21.19-26.04)$ & $24.01(21.15-25.89)$ & 0.575 \\
\hline Sex & $191(60.1)$ & $21(46.7)$ & \\
\hline Male & $127(39.9)$ & $24(53.3)$ & 0.088 \\
\hline Female & $1(0-3)$ & $2(1-3)$ & \\
\hline Charlson comorbidity index & $8(2.5)$ & $1(2.2)$ & $\mathbf{0 . 0 3 6}$ \\
\hline Myocardial infarction & $5(1.6)$ & $1(2.2)$ & 1.000 \\
\hline Congestive heart failure & $4(1.3)$ & $14(31.1)$ & 0.551 \\
\hline Peripheral vascular disease & $25(7.9)$ & $5(11.1)$ & $<\mathbf{0 . 0 0 0 1}$ \\
\hline Cerebrovascular disease & $11(3.5)$ & $0(0.0)$ & 0.398 \\
\hline Dementia & $2(0.6)$ & $0(0.0)$ & 0.372 \\
\hline Chronic pulmonary disease & $14(4.4)$ & $3(6.7)$ & 1.000 \\
\hline Connective tissue disease & $1(0.3)$ & $1(2.2)$ & 0.454 \\
\hline Ulcer disease & $5(1.6)$ & $0(0.0)$ & 0.233 \\
\hline Mild liver disease & $3(0.9)$ & $0(0.0)$ & 1.000 \\
\hline Liver cirrhosis & $55(17.3)$ & $10(22.2)$ & 1.000 \\
\hline $\begin{array}{c}\text { Diabetes without end-organ } \\
\text { damage }\end{array}$ & $3(0.9)$ & $0(0.0)$ & 0.420 \\
\hline Diabetes with end-organ damage & $0(0.0)$ & 1.000 \\
\hline Chronic kidney disease or dialysis & $4(1.3)$ & $2(4.4)$ & 1.000 \\
\hline Tumor-localized & $16(5.0)$ & $0(0.0)$ & 1.000 \\
\hline Tumor-Metastasis & $1(0.3)$ & $1(2.2)$ & 1.000 \\
\hline Leukemia & $0(0.0)$ & & 0.124 \\
\hline
\end{tabular}

Table 1. Baseline demographics of the patients without and with venous thromboembolism (VTE). Nonnormally distributed numerical variables are presented by median (Q1-Q3) and tested by Wilcoxon rank-sum test, and categorical variables are presented by $\mathrm{N}(\%)$ and tested by chi-squared test or Fisher's exact test.

\begin{tabular}{|l|l|c|}
\hline Fracture location & N & \% \\
\hline Acetabulum & 28 & 6.5 \\
\hline Pelvis & 17 & 3.9 \\
\hline Femur neck & 19 & 4.4 \\
\hline Femur Intertrochanteric & 54 & 12.5 \\
\hline Femur subtrochanteric & 10 & 2.3 \\
\hline Femur shaft & 60 & 13.9 \\
\hline Distal femur & 31 & 7.2 \\
\hline Proximal tibia & 42 & 9.7 \\
\hline Tibia shaft & 34 & 7.9 \\
\hline Distal tibia & 61 & 14.2 \\
\hline Ankle & 75 & 17.4 \\
\hline Total & 431 & 100.0 \\
\hline
\end{tabular}

Table 2. Fracture location according to the anatomy of the bone involved.

75 cases of ankle fracture (Table 2). Sixty-five patients had multiple fractures involving 2 or more anatomical locations. Forty-five patients (12.4\%) were diagnosed with symptomatic VTE. DVT and PE occurred in $34(9.4 \%)$ and $19(5.2 \%)$ patients, and 8 patients $(2.2 \%)$ were diagnosed with both DVT and PE. Twelve patients (3.3\%) were diagnosed with VTE before definitive fixation surgery, and 3 of those were diagnosed as pulmonary embolism. These patients developed VTE on average $6.3 \pm 8.6$ days from the date of injury. Thirty-three patients $(9.1 \%)$ were diagnosed with a VTE that occurred after definitive fixation surgery, with the events occurring an average of $6.6 \pm 7.6$ days after surgery, and 16 of those were diagnosed as pulmonary embolism. Thirteen patients (3.6\%) were diagnosed with distal DVT, and 3 of those coexisted with PE. Thirteen patients (3.6\%) were also diagnosed with proximal DVT, and 3 of those coexisted with PE. Eight patients (2.2\%) were diagnosed to have both proximal and distal DVT in the same lower extremity, and 2 of those coexisted with PE.

For treatment, either Enoxaparin or Dalteparin via subcutaneous injection at treatment dose was used for 5-7 days and oral medication (e.g. dabigatran) was continued for 3 months. In a single case of PE, an emergency thrombectomy was required. (Fig. 1).

None of the patients suffered from wound complications requiring hematoma evacuation, cessation of pharmacologic agents, or surgical management. Furthermore, none of the patients suffered from major bleeding complication defined as any intracranial, intraocular, retroperitoneal, intraspinal, or pericardial bleeding ${ }^{19}$. 


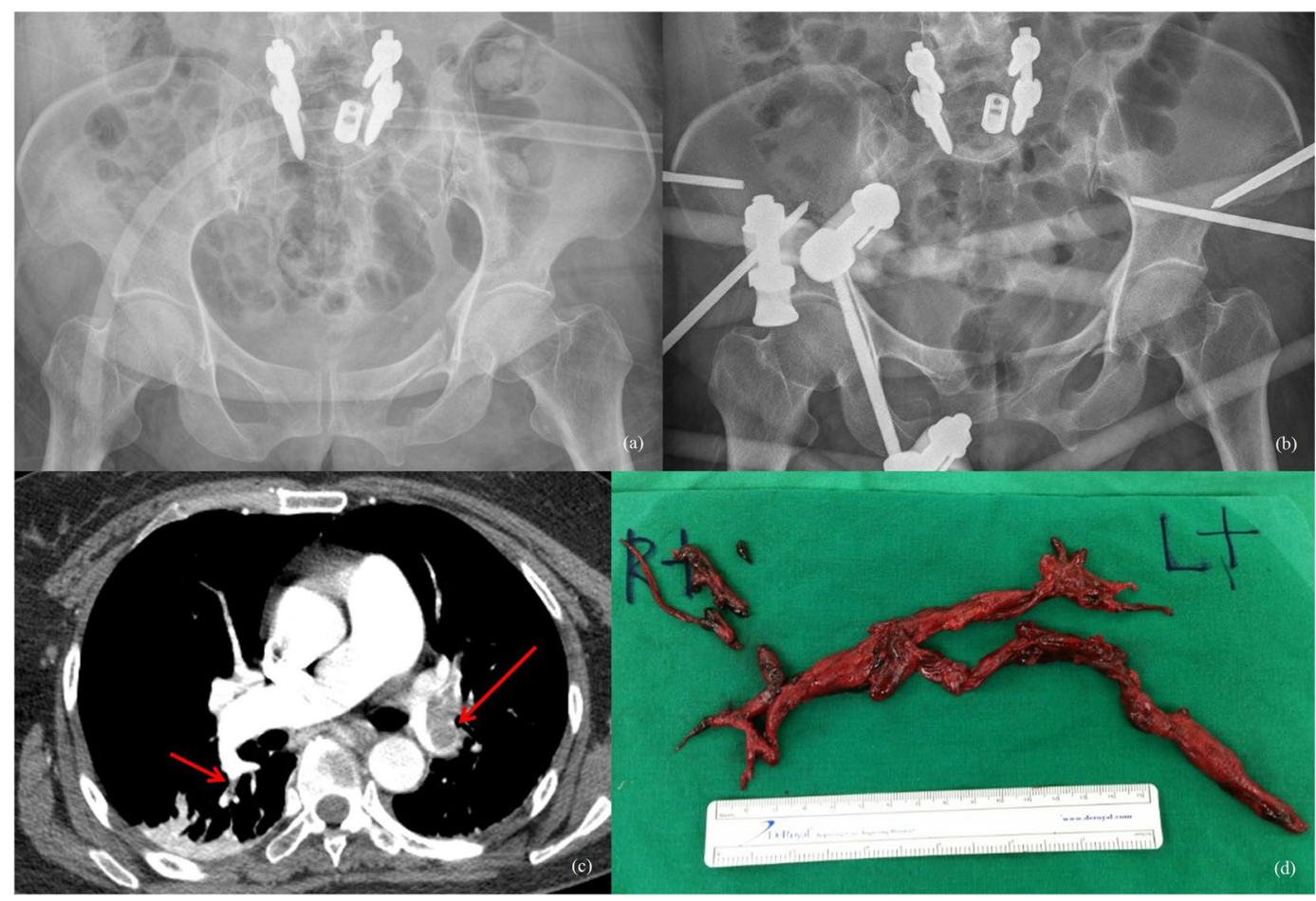

Figure 1. A 52-year-old female patient with a left rami fracture and diastasis of the left SI joint after a traffic accident underwent general anaesthesia for pelvic ring stabilization (a). After general anaesthesia, the patient rapidly developed hypoxia and tachycardia and the operation was not performed. Only external fixation was performed (b). CT angiography was performed to confirm total occlusion of the left pulmonary artery and right segmental thrombus (red arrow) (c). Thrombectomy was immediately performed (d).

Univariate analysis showed that a history of external fixator application $(\mathrm{p}=0.020)$ and open fractures $(\mathrm{p}=0.011)$ were associated with increased VTE risk in this study. After stepwise multivariable regression analysis, a higher Charlson comorbidity index $(\mathrm{p}=0.037)$ and a history of external fixator application $(\mathrm{p}=0.007)$ were associated with increased VTE risk (Table 3). Subgroup analysis within patients who had VTE (e.g., patients with PE versus VTE patients without PE) revealed that male sex $(\mathrm{p}=0.017)$ and above-the-knee fracture $(\mathrm{p}=0.035)$ were associated with increased PE risk (Table 4). However, the location of the DVT was not significantly correlated with occurrence of $\mathrm{PE}(\mathrm{p}=1.000)$.

\section{Discussion}

The present study was conducted to investigate the incidence of symptomatic VTE after receiving chemoprophylaxis in patients who underwent surgery for pelvic and lower-extremity fractures, and to identify the risk factors for VTE occurrence in this subgroup of patients. In this study, the incidence of symptomatic VTE detected by CT angiography was $12.4 \%$ (45 out of 363 patients), and the incidence of symptomatic PE was $5.2 \%$ (19 out of 363 patients). For the risk-factor analysis, a higher Charlson comorbidity index and a history of external fixator application were associated with increased VTE risk. Among patients who had VTE, male sex, and above-the-knee fractures were associated with increased PE risk.

Although the reported incidences of symptomatic and fatal thromboembolic events are low, the risk of symptomatic VTE has changed little over the past 20 years ${ }^{20,21}$. There is a general agreement that prophylaxis against VTE is necessary in post-traumatic patients, but a tendency to underestimate this complication persists, as the majority of patients with small or asymptomatic VTEs do not come under clinical suspicion and are therefore never evaluated ${ }^{22}$.

It has been recommended that post-traumatic patients receive pharmacologic prophylaxis and/or be treated with an intermittent pneumatic compressive device, rather than receive no prophylaxis ${ }^{11-15}$. A gold standard for prophylaxis has yet to be identified. In a study by Stannard et al., although the incidence of VTE following chemotherapy alone was $13.4 \%$, the incidence fell further to $8.7 \%$ when both drugs and mechanical methods were used $^{23}$. However, application of a pneumatic compressive device in patients with corresponding lower extremity fractures may not be possible. Traditionally, orthopaedic surgeons have been concerned about the effects of VTE prophylaxis on perioperative bleeding, which can result in hematoma, infection and wound problems. There has also been a concern that patients at low risk of developing symptomatic VTE may receive excessive anticoagulation ${ }^{24}$. Accordingly, updated guidelines from both the American Academy of Orthopaedic Surgeons and the American College of Clinical Pharmacy have focused more on the safety of prophylactic agents and symptomatic and fatal VTE events ${ }^{25,26}$. 


\begin{tabular}{|c|c|c|c|c|c|c|}
\hline \multirow[b]{2}{*}{ Variables } & \multicolumn{3}{|c|}{ Univariable } & \multicolumn{3}{|c|}{ Multivariable } \\
\hline & $\begin{array}{l}\text { Odds } \\
\text { ratio }\end{array}$ & 95\% C.I. & $P$-value & $\begin{array}{l}\text { Odds } \\
\text { ratio }\end{array}$ & 95\% C.I. & $P$-value \\
\hline Age & 1.01 & $0.99-1.03$ & 0.214 & & & \\
\hline Body mass index & 1.01 & $0.96-1.08$ & 0.655 & & & \\
\hline Sex (Female) & 1.72 & $0.92-3.22$ & 0.091 & & & \\
\hline $\begin{array}{l}\text { Multiple fracture (vs } \\
\text { single) }\end{array}$ & 1.53 & $0.71-3.29$ & 0.275 & & & \\
\hline $\begin{array}{l}\text { Injury severity score } \\
(>8)\end{array}$ & 1.68 & $0.46-6.13$ & 0.435 & & & \\
\hline $\begin{array}{l}\text { Below knee fracture } \\
\text { (vs above knee } \\
\text { fracture) }\end{array}$ & 1.33 & $0.69-2.55$ & 0.399 & & & \\
\hline $\begin{array}{l}\text { Charlson } \\
\text { comorbidity index }\end{array}$ & 1.13 & $0.98-1.30$ & 0.102 & 1.18 & $1.01-1.38$ & 0.037 \\
\hline $\begin{array}{l}\text { External fixation } \\
\text { (yes) }\end{array}$ & 2.34 & $1.15-4.79$ & 0.020 & 2.98 & $1.34-6.60$ & 0.007 \\
\hline Open (vs closed) & 2.53 & $1.23-5.19$ & 0.011 & & & \\
\hline Flap (yes) & 2.96 & $0.79-11.09$ & 0.107 & & & \\
\hline \multicolumn{7}{|c|}{ Gustilo classification grade } \\
\hline 1 & $<0.001$ & $<0.001->999.999$ & 0.962 & & & \\
\hline 2 & 0.29 & $0.06-1.50$ & 0.140 & & & \\
\hline 3 & Ref. & & & & & \\
\hline
\end{tabular}

Table 3. The association of demographic and clinical variables on occurrence of venous thromboembolism (VTE) assessed by logistic regression analysis.

\begin{tabular}{|c|c|c|c|c|c|c|}
\hline \multirow[b]{2}{*}{ Variables } & \multicolumn{3}{|c|}{ Univariable } & \multicolumn{3}{|c|}{ Multivariable } \\
\hline & $\begin{array}{l}\text { Odds } \\
\text { ratio }\end{array}$ & 95\% C.I. & $P$-value & $\begin{array}{l}\text { Odds } \\
\text { ratio }\end{array}$ & 95\% C.I. & $P$-value \\
\hline Age & 1.00 & $0.97-1.03$ & 0.924 & & & \\
\hline Body mass index & 1.01 & $0.89-1.15$ & 0.853 & & & \\
\hline Sex (Female) & 0.21 & $0.06-0.74$ & 0.015 & 0.16 & $0.03-0.71$ & 0.017 \\
\hline $\begin{array}{l}\text { Open fracture (vs } \\
\text { closed) }\end{array}$ & 0.50 & $0.13-1.98$ & 0.326 & & & \\
\hline $\begin{array}{l}\text { Multiple fracture (vs } \\
\text { single) }\end{array}$ & 2.54 & $0.60-10.70$ & 0.205 & & & \\
\hline $\begin{array}{l}\text { Injury severity score } \\
(>8)\end{array}$ & 2.94 & $0.25-35.06$ & 0.394 & & & \\
\hline $\begin{array}{l}\text { Below knee fracture (vs } \\
\text { above knee fracture) }\end{array}$ & 0.27 & $0.07-1.01$ & 0.052 & 0.20 & $0.04-0.89$ & 0.035 \\
\hline $\begin{array}{l}\text { Charlson comorbidity } \\
\text { index }\end{array}$ & 0.92 & $0.67-1.26$ & 0.606 & & & \\
\hline External fixation (yes) & 0.50 & $0.13-1.98$ & 0.326 & & & \\
\hline
\end{tabular}

Table 4. The association of demographic and clinical variables on occurrence of pulmonary embolism (PE) among patients with venous thromboembolism (VTE) assessed by logistic regression analysis.

The reported incidence of post-traumatic VTE ranges between $2.6 \%$ and $63 \%$, depending on the demographics of the study population, the nature of the injuries, type of prophylaxis used, and method to detect the lesions ${ }^{7-10}$. Abelseth et al. studied the incidence of DVT in 176 patients who had undergone operative fixation for fractures of the lower extremity distal to the hip and reported a $28 \%$ incidence of DVT (mostly distal asymptomatic DVTs) detected by screening for venography ${ }^{16}$. Goel et al. performed a randomised controlled trial of treating 238 patients who had undergone operative fixation for fractures of below-the-knee lower extremity with placebo or low-molecular-weight heparin (LMWH) and reported no significant difference in the incidence of DVT (8.7\% in LMWH group vs $12.6 \%$ in placebo group) as detected by screening venography ${ }^{17}$. Niikura et al. studied the rate of VTE after complex lower-extremity fracture surgery consisting of temporary external fixator application followed by definitive internal fixation, and found a high incidence of VTE $(38.5 \%, 15$ out of 39 patients) was detected by contrast-enhanced CT without pharmacological prophylaxis, although no PEs were fatal ${ }^{18}$. In the present study, pelvic and lower-extremity fractures were assessed for symptomatic VTEs. The incidence of symptomatic VTE detected by CT angiography was $12.4 \%$ (45 out of 363 patients) and the incidence of symptomatic PE was 5.2\% (19 out of 363 patients) with pharmacological prophylaxis applied. Although not directly comparable, the incidence of symptomatic VTE in the present study was high in post-traumatic patients with lower-extremity fractures, even with pharmacological prophylaxis. 
Knudson et al. identified 450,375 trauma patients and the risk factors associated with development of VTE ${ }^{27}$. They reported an age of over 40 years, a lower-extremity fracture more than 3 points in abbreviated injury scale (AIS), applying a ventilator for more than 3 days, a head injury more than 3 points in AIS, venous injury, and cases requiring major operative procedure as risk factors. Wahlsten et al. studied 57,619 trauma patients and found that the incidence of VTE was low following surgery for fractures distal to the knee, but the risk increased with the presence of risk factors including use of oral contraception by patients eighteen to fifty years of age, previous DVT, previous PE, coagulopathy, and peripheral artery disease ${ }^{28}$. Furthermore, Thorson et al. prescreened 534 trauma patients with a risk assessment profile, and reported that high-risk profile score and pelvic fracture with prolonged intervention are independent predictors for VTE development, despite thromboprophylaxis ${ }^{29}$. However, few studies have reported the association between VTE incidence and patient factors such as sex, BMI, and underlying disease in trauma patients with fractures. In the present study, a higher Charlson comorbidity index and a history of external fixator application were associated with increased VTE risk. Among conditions for Charlson comorbidity index scoring, there were significantly higher proportion of patients with a history of peripheral vascular disease in patients who had VTE compared to patients without VTE (31.3\% vs 1.3\%, $\mathrm{p}<0.001$ ), and this may have influenced the results. Among patients who had VTE, male sex, and above-the-knee fractures were associated with increased PE risk. It is noteworthy that patients who had external fixator application were associated with increased VTE risk, and a longer period of immobilization would have contributed to thrombus formation in the vessels ${ }^{4}$. For the PE risk, up to $40 \%$ of proximal DVTs have an association with PE, and above-the-knee fractures would have caused more injury to the proximal vein, leading to formation and emboli of the thrombus at a more proximal area $^{30}$. It was surprising to find being male as a risk factor for PE. Several studies have assessed the relationship between sex and incidence of VTE, and found the VTE recurrence rate is consistently higher in men, suggesting that higher prevalence of PE-associated proximal DVT in men partly accounts for the higher VTE recurrence rate in $\mathrm{men}^{31,32}$. It is possible that the higher prevalence of PE-associated proximal DVT in men, as with above-the-knee fractures being a risk factor for PE, is associated with PE risk in patients with pelvic and lower-extremity fractures.

This study has several limitations. First, two different LMWHs were used as there was institutional formulary change in LMWH prophylaxis from Dalteparin to Enoxaparin. However, as effectiveness of Dalteparin and Enoxaparin for thromboprophylaxis after traumatic injury has been reported to be similar by numerous studies $^{33-35}$, the effect of differing LMWH prophylaxis on VTE occurrence should have been minimal. In a study that included 5880 trauma patients, the VTE rate was 3.3/1000 days in the Enoxaparin period vs 3.8/1000 days in Dalteparin period proving similar prophylactic effect of both LMWHs in trauma patients ${ }^{33}$. Second, only patients eligible to use pharmacological anti-coagulation prophylaxis were enrolled. Patients with co-existing head, chest, or abdominal trauma requiring treatment were excluded from the study. The findings in our study cannot be generalised to severely traumatised patients with a high ISS or those requiring intensive-care unit hospitalization. Third, as this was a single-institution study, it may not reflect universal practices, and the number of patients assessed was relatively small, accounting for the low incidence of PE. Fourth, symptoms of VTE were subjectively assessed by the senior surgeon, and selection bias issue may be an issue. Fifth, it is not possible to directly compare the results between studies due to inhomogeneity in study populations, VTE prophylaxis, and detection methods. Finally, other factors including use of oral contraception, timing of weight bearing, and ankle mobilization were not thoroughly assessed.

Despite pharmacological prophylaxis, the incidence of symptomatic VTE detected by CT angiography was $12.4 \%$ (45 out of 363 patients), and the incidence of symptomatic PE was 5.2\% (19 of 363 patients). A higher Charlson comorbidity index and a history of external fixator application were associated with increased VTE risk. Male sex, and above-the-knee fracture were associated with increased PE risk. In such high-risk patients close monitoring with more aggressive prophylactic regimens may be beneficial.

\section{Materials and Methods}

Study population. The Institutional Review Board of Hanyang University hospital approved the study, and all patients provided informed consent. All procedures performed in this study involving human participants were in accordance with ethical standards of the institutional and/or national research committee and with the 1964 Helsinki Declaration and its later amendments or comparable ethical standards. Between March 2012 and July 2017, 392 patients who underwent surgery for acute pelvic bone and lower extremity fractures were assessed retrospectively. Exclusion criteria included a history of thromboembolic disease; the use of anticoagulants; renal insufficiency; liver cirrhosis and hepatitis; a history of haemorrhagic disease; co-existing brain, thoracic or abdominal trauma requiring treatment; combined upper extremity fractures; and simple lower-extremity fractures involving foot or patella. A total of 363 patients were enrolled in the study. All patients underwent pharmacologic treatment immediately after admission (within 12 hours of initial presentation) to prevent VTE and treatment continued until partial weighted crutch walking or active range of motion on injured lower extremity was possible. Patients received LMWH, either Enoxaparin or Dalteparin, via subcutaneous injection at a dose of $40 \mathrm{mg} /$ day and 5000 units/day, respectively. Two different LMWH formulations were used as there was institutional formulary change in LMWH prophylaxis from Dalteparin to Enoxaparin in 2015.

Patients were not routinely screened for VTE, and only those with symptoms or signs suggestive of VTE were assessed for definitive diagnosis. Clinical signs suggestive of symptomatic DVT, including pain and marked swelling of the corresponding calf or thigh, tenderness on indurated venous segment, Homan's sign, variable skin discoloration of the lower extremity, and prominence of superficial veins were evaluated daily ${ }^{36}$. PE, defined as symptomatic when a patient had symptoms such as dyspnoea, tachypnoea, chest pain, and cough, was suspected with sudden hypoxia $\left(\mathrm{O}_{2}\right.$ saturation $\left.<95 \%\right)$ or hypoxemia $\left(\mathrm{PaO}_{2}<83 \mathrm{mmHg}\right)^{37}$. To detect VTE, 64-channel multidetector computed tomography (Brilliance $64^{\circledR}$, Philips, Eindhoven, the Netherlands) was performed (Fig. 2). 


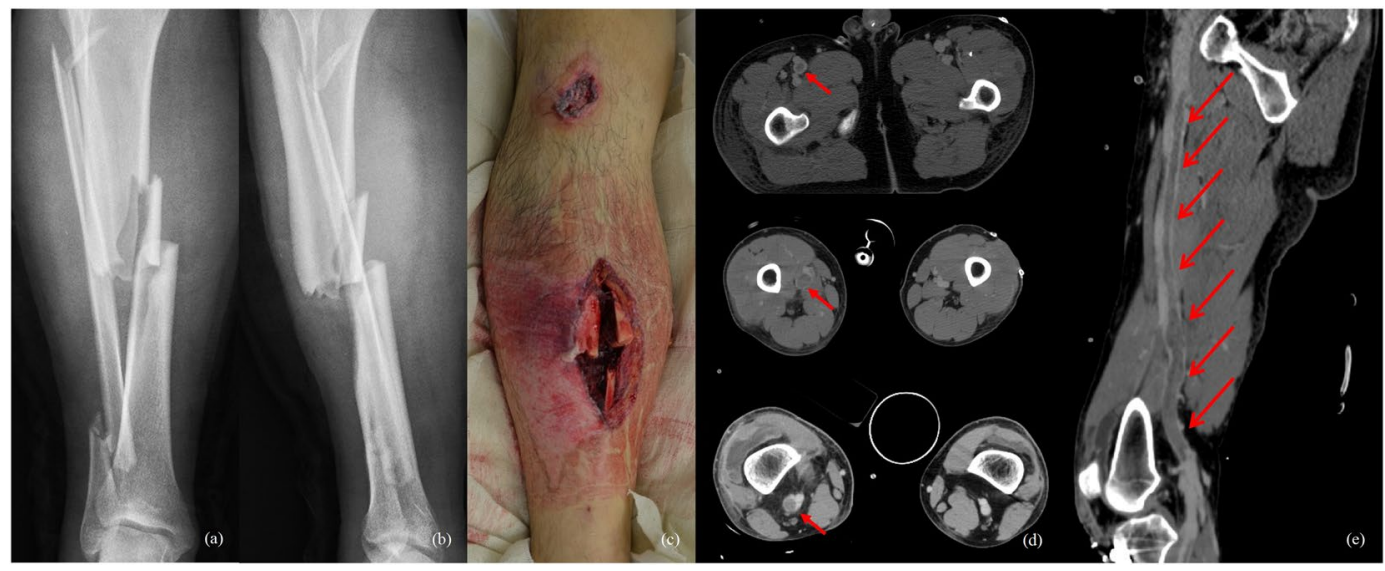

Figure 2. A 41-year-old male patient with right tibio-fibular open fracture and left ankle fracture after a motorcycle accident developed right lower-extremity severe swelling and pain during passive ankle and toe motion (a-c). CT angiography was performed. A massive thrombus in the right common femoral vein and calf were confirmed (red arrow) and chemical treatment was administered continuously (d,e).

To evaluate risk factors for VTE, demographic and clinical data were collected from medical records (Table 1). Fracture location was defined according to the anatomy of the bone involved (e.g., acetabulum, pelvis, femur, tibia, or ankle) (Table 2). Multiple fractures were defined as fractures involving at least 2 locations. Because DVT in the pelvis and lower extremities proximal to the popliteal artery is the most frequent source of emboli in the pulmonary artery ${ }^{30}$, fracture location was further classified as proximal to the fracture in an area proximal to a knee joint (e.g., acetabulum, pelvis, and femur) and as distal when the fracture was limited to an area distal to a knee joint (e.g., tibia and ankle). The injury severity score (ISS) scale was used to represent the severity of the injuries, which were categorised as mild $(<9)$, moderate $(9-15)$, or severe $(16-25)^{38}$. Gustilo open-fracture classification was used to grade open fractures ${ }^{39}$. The Charlson comorbidity index ${ }^{40}$ which contains 19 issues including diabetes with diabetic complications, congestive heart failure, peripheral vascular disease (intermittent claudication, prior bypass for chronic arterial insufficiency, history of gangrene, acute arterial insufficiency, untreated aneurysm $\geq 6 \mathrm{~cm}$ ), chronic pulmonary disease, liver disease, hemiplegia, renal disease, leukemia, lymphoma, and metastatic tumor was used to categorize comorbidities of patients (Table 1).

Statistical analysis. Statistical significance was tested using a Wilcoxon rank-sum test, Pearson's chi-squared test, and Fisher's exact test as appropriate. Non-normally distributed numerical variables were tested by Wilcoxon rank-sum test, and categorical variables were tested by either chi-squared test or Fisher's exact test. Factors including sex, age, body mass index (BMI), Charlson comorbidity index, and injury-related variables (single versus multiple fracture, proximal versus distal fracture, ISS, and severity of open fracture) were assessed with logistic regression analysis. Stepwise linear regression analysis was performed and a model was selected based on the value of Akaike's Information Criterion. Statistical significance was set at 0.05 and SAS version 9.4 (SAS Institute Inc., Cary, NC, USA) and R package version 3.5.1 were used for all analyses.

\section{Data availability}

All data analysed during this study are available from the corresponding author on reasonable request.

Received: 16 October 2019; Accepted: 12 March 2020;

Published online: 25 March 2020

\section{References}

1. Raskob, G. E., Silverstein, R., Bratzler, D. W., Heit, J. A. \& White, R. H. Surveillance for deep vein thrombosis and pulmonary embolism: recommendations from a national workshop. Am J Prev Med. 38, S502-S509 (2010).

2. Ashrani, A. A. \& Heit, J. A. Incidence and cost burden of post-thrombotic syndrome. J Thromb Thrombolysis. 28, 465-476 (2009).

3. Ruppert, A., Lees, M. \& Steinle, T. Clinical burden of venous thromboembolism. Curr Med Res Opin. 26, 2465-2473 (2010).

4. Cushman, M. Epidemiology and risk factors for venous thrombosis. Semin Hematol. 44, 62-69 (2007).

5. Bendinelli, C. \& Balogh, Z. Postinjury thromboprophylaxis. Curr Opin Crit Care. 14, 673-678 (2008).

6. Brohi, K. et al. Acute coagulopathy of trauma: hypoperfusion induces systemic anticoagulation and hyperfibrinolysis. J Trauma. 64, 1211-1217 (2008).

7. Coon, W. W. Epidemiology of venous thromboembolism. Ann Surg. 186, 149-164 (1977).

8. Kudsk, K. A. et al. Silent deep vein thrombosis in immobilized multiple trauma patients. Am J Surg. 158, 515-519 (1989).

9. Dunbar, N. M. \& Chandler, W. L. Thrombin generation in trauma patients. Transfusion. 49, 2652-2660 (2009).

10. Cho, Y. H., Byun, Y. S., Jeong, D. G., Han, I. H. \& Park, Y. B. Preoperative incidence of deep vein thrombosis after hip fractures in Korean. Clin Orthop Surg. 7, 298-302 (2015).

11. Ruskin, K. J. Deep vein thrombosis and venous thromboembolism in trauma. Curr Opin Anaesthesiol. 31, 215-218 (2018).

12. Paffrath, T. et al. Venous thromboembolism after severe trauma: incidence, risk factors and outcome. Injury. 41, 97-101 (2010).

13. Kwak, H. S., Cho, J. H., Kim, J. T., Yoo, J. J. \& Kim, H. J. Intermittent pneumatic compression for the prevention of venous thromboembolism after total hip arthroplasty. Clin Orthop Surg. 9, 37-42 (2017).

14. Chung, K. S., Shin, T. Y., Park, S. H., Kim, H. \& Choi, C. H. Rivaroxaban and acetylsalicylic acid for prevention of venous thromboembolism following total knee arthroplasty in Korean patients. Knee Surg Relat Res. 30, 247-254 (2018). 
15. Buesing, K. L., Mullapudi, B. \& Flowers, K. A. Deep venous thrombosis and venous thromboembolism prophylaxis. Surg Clin North Am. 95, 285-300 (2015).

16. Abelseth, G., Buckley, R. E., Pineo, G. E., Hull, R. \& Rose, M. S. Incidence of deep-vein thrombosis in patients with fractures of the lower extremity distal to the hip. J Orthop Trauma. 10, 230-235 (1996).

17. Goel, D. P. et al. Prophylaxis of deep-vein thrombosis in fractures below the knee: a prospective randomised controlled trial. J Bone Joint Surg Br. 91, 388-394 (2009).

18. Niikura, T. et al. Rate of venous thromboembolism after complex lower-limb fracture surgery without pharmacological prophylaxis. J Orthop Surg. 23, 37-40 (2015).

19. Colwell, C. W. Jr. et al. Oral direct thrombin inhibitor ximelagatran compared with warfarin for the prevention of venous thromboembolism after total knee arthroplasty. J Bone Joint Surg Am. 87, 2169-2177 (2005).

20. Geerts, W. H. et al. Prevention of venous thromboembolism: American college of chest physicians evidence-based clinical practice guidelines (8th Edition). Chest. 133, 381S-453S (2008).

21. Pedersen, A. B., Mehnert, F., Johnsen, S. P., Husted, S. \& Sorensen, H. T. Venous thromboembolism in patients having knee replacement and receiving thromboprophylaxis: a Danish population-based follow-up study. J Bone Joint Surg Am. 93, 1281-1287 (2011).

22. Kroegel, C. \& Reissig, A. Principle mechanisms underlying venous thromboembolism: epidemiology, risk factors, pathophysiology and pathogenesis. Respiration. 70, 7-30 (2003).

23. Stannard, J. P. et al. Prophylaxis against deep-vein thrombosis following trauma: a prospective, randomized comparison of mechanical and pharmacologic prophylaxis. J Bone Joint Surg Am. 88, 261-266 (2006).

24. Johanson, N. A. et al. American academy of orthopaedic surgeons clinical practice guideline on. prevention of symptomatic pulmonary embolism in patients undergoing total hip or knee arthroplasty. J Bone Joint Surg Am. 91, 1756-1757 (2009).

25. Mont, M. A. \& Jacobs, J. J. AAOS clinical practice guideline: preventing venous thromboembolic disease in patients undergoing elective hip and knee arthroplasty. J Am Acad Orthop Surg. 19, 777-778 (2011).

26. Falck-Ytter, Y. et al. Prevention of VTE in orthopedic surgery patients: antithrombotic therapy and prevention of thrombosis, $9^{\text {th }}$ ed: American college of chest physicians evidence-based clinical practice guidelines. Chest. 141, e278S-e325S (2012).

27. Knudson, M. M., Ikossi, D. G., Khaw, L., Morabito, D. \& Speetzen, L. S. Thromboembolism after trauma: an analysis of 1602 episodes from the American college of surgeons national trauma data bank. Ann Surg. 240, 490-496 (2004).

28. Wahlsten, L. R. et al. Symptomatic venous thromboembolism following fractures distal to the knee: a nationwide Danish cohort study. J Bone Joint Surg Am. 97, 470-477 (2015).

29. Thorson, C. M. et al. Venous thromboembolism after trauma: a never event? Crit Care Med. 40, 2967-2973 (2012).

30. Wilbur, J. \& Shian, B. Diagnosis of deep venous thrombosis and pulmonary embolism. Am Fam Physician. 86, 913-919 (2012).

31. Roach, R. E., Cannegieter, S. C. \& Lijfering, W. M. Differential risks in men and women for first and recurrent venous thrombosis: the role of genes and environment. J Thromb Haemost. 12, 1593-1600 (2014).

32. Christiansen, S. C., Lijfering, W. M., Helmerhorst, F. M., Rosendaal, F. R. \& Cannegieter, S. C. Sex difference in risk of recurrent venous thrombosis and the risk profile for a second event. J Thromb Haemost. 8, 2159-2168 (2010).

33. Miano, T. A. et al. Comparative effectiveness of enoxaparin vs dalteparin for thromboprophylaxis after traumatic injury. Chest. 153, $133-142$ (2018)

34. Okoye, O. T. et al. Dalteparin versus enoxaparin for the prevention of venous thromboembolic events in trauma patients. Eur J Trauma Emerg Surg. 40, 183-189 (2014).

35. Chiou-Tan, F. Y. et al. Comparison of dalteparin and enoxaparin for deep venous thrombosis prophylaxis in patients with spinal cord injury. Am J Phys Med Rehabil. 82, 678-685 (2003).

36. Kapoor, C. S., Mehta, A. K., Patel, K. \& Golwala, P. P. Prevalence of deep vein thrombosis in patients with lower limb trauma. J Clin Orthop Trauma. 7, 220-224 (2016).

37. Konstantinides, S. V. et al. 2014 ESC guidelines on the diagnosis and management of acute pulmonary embolism. Eur Heart J. 35, 3033-3080 (2014).

38. Bolorunduro, O. B. et al. Validating the injury severity score in different populations: ISS predicts mortality better among hispanics and females. J Surg Res. 166, 4-44 (2011).

39. Kim, P. H. \& Leopold, S. S. Gustilo-Anderson classification. Clin Orthop Relat Res. 470, 3270-3274 (2012).

40. Charlson, M. E., Pompei, P., Ales, K. L. \& MacKenzie, C. R. A new method of classifying prognostic comorbidity in longitudinal studies: development and validation. J Chronic Dis. 40, 373-383 (1987).

\section{Author contributions}

K.T.H. and J.K.L. were responsible for designing the study. J.W.K. was responsible for preparing the manuscript content. S.Y.J. and S.H.C. contributed on data collecting. K.C.P. contributed on revising the manuscript content.

\section{Competing interests}

The authors declare no competing interests.

\section{Additional information}

Supplementary information is available for this paper at https://doi.org/10.1038/s41598-020-62333-z.

Correspondence and requests for materials should be addressed to K.-T.H.

Reprints and permissions information is available at www.nature.com/reprints.

Publisher's note Springer Nature remains neutral with regard to jurisdictional claims in published maps and institutional affiliations.

(c) (i) Open Access This article is licensed under a Creative Commons Attribution 4.0 International

License, which permits use, sharing, adaptation, distribution and reproduction in any medium or format, as long as you give appropriate credit to the original author(s) and the source, provide a link to the Creative Commons license, and indicate if changes were made. The images or other third party material in this article are included in the article's Creative Commons license, unless indicated otherwise in a credit line to the material. If material is not included in the article's Creative Commons license and your intended use is not permitted by statutory regulation or exceeds the permitted use, you will need to obtain permission directly from the copyright holder. To view a copy of this license, visit http://creativecommons.org/licenses/by/4.0/.

(c) The Author(s) 2020 